\title{
Parent-Child Attachment, Parental Depression, and Perception of Child Behavioural/Emotional Problems
}

\author{
Lawrence T. Lam \\ Additional information is available at the end of the chapter \\ http://dx.doi.org/10.5772/51170
}

\section{Introduction}

The issue of whether parents who have experienced symptoms of psychopathology, particularly depression, would be able to provide an accurate report on the behavioural/emotional problems of their children has long been raised. [1] It has been suggested that parental depression plays an important role in their perception of their children's behavioural. [2-7] The early review by Breslau (1988) on the available studies in 1988 found that there was no evidence for any distortion of child behavioural problems using depressed mothers as informants. [1] However, more recent studies have found a positive relationship between parental depression, particularly maternal depression, and report of increased behavioural/emotional problems of their children. For example, in the study by Fergussen et al. on the effect of maternal depression on their ratings of children behaviour found a significant association between their depression and children's conduct disorder and attention deficit behaviour. [3] A recent study by Hall et al. also found that depressive symptoms in mothers contributed significantly to the perception of both internalising and externalising problems of their children when they were asked to report on their children's behaviour [7].

Parent-child relationships, particularly attachment or connectedness between the parent and child, have been reported to have an effect on the behavioural and emotional health of children and adolescents. [8-9] In terms of the parent-child relationship and parental perception of their children's behavioural and emotional problems, it has been noted that few studies have been conducted. [5] The study by Kolko et al. found that low parental acceptance of the child was significantly associated with the difference between parents' and teachers' perception of children's externalising but not internalising behaviour. [10] Another study by Mosley et al. also found that better parent-child relationships in terms of increased involvement also related to a decrease of parental perception on both internalising and externalising be- 
havioural problems. [11] A more recent study by Treulter \& Epkins also found that the parent-child relationship, measured as parental involvement and time spent with children, was significantly related to both parents' rating of externalising behaviour. [5] In sum, these studies suggested an overall negative association between parent-child relationships and their perception on children's behavioural/emotional problems such that the better the parent-child relationship, the less the degree of parental perception of children's behavioural/ emotional problems.

The above-mentioned studies have suggested both parental depressive symptoms and parent-child relationships are associated with parent's perception of children's behavioural/ emotional problems. However, the foci of all these studies are on individual variables, either parental depressive symptoms or parent-child relationships, and their associations with parental perception. All of the above-mentioned studies considered only one of the two factors with the exception of the study by Treulter \& Epkins. [5] It has been known that parental depression, particularly maternal depression, exerts a significant influence on the parentchild relationship. [12] Therefore, it is logical to consider that there could be an interaction effect of parental depression and parent-child relationship on parent's perception of children's behavioural/emotional problems. A search of the current literature has revealed no related studies on this topic.

The aim of this study is to further examine the relationships between parental depression, parent-child relationship and parental perception of children's behavioural/emotional problems. Of particular interest of the study is the possible interaction effect between parental depression and parent-child relationship, specifically parent-child attachment or connectedness, on the perception of children's behavioural/emotional problems. It is hypothesised that the parent-child relationship acts as an effect modifier in the relationship between parental depression and the perception of children's behavioural/emotional problems in a manner that depressed parents who also have inadequate attachment or connectedness with their children would have a significantly increased rating on their children's behavioural/ emotional problems.

\section{Methods}

This cross-sectional survey is part of the Guangzhou city primary school students' behavioural problems intervention longitudinal cohort study. The survey serves as the base-line pre-intervention data collected on participating school children and their parents as well as a screening for behavioural problems among children. The cohort study is an on-going study conducted in the YueXiu district, the biggest district of the Guangzhou city in Guangdong Province, since December 2008. Guangdong Province is located in Southern China, and is the most populous province in China of which Guangzhou city is the capital. It is the biggest and most populated city of the Province with an estimated population of nearly 10 million in 2006. Institute ethics approval for the study was granted by the Human Ethics Committee of the Sun Yat-Sen University, GuangZhou, PR China. 
The sample was generated from the total student population of grade 4 primary school children within the study district. All students were registered with the Guangzhou city primary school registry. According the latest information from the registry, there were about 8400 grade 4 primary school children enrolled within the study district in 2008. A stratified random sampling method with stratification according to proportions of students in different type of schools: schools run by provincial government, local government, or private schools, were used for sample generation.

The base-line survey was conducted at different schools within the same week. Parents of the selected students from different schools were invited to participate in the longitudinal study via school principals and their teachers, and were encouraged to fill in the baseline self-reported questionnaire designed specifically for the study. Informed consent was sought from each parent by signing a consent form indicating willing participation in the longitudinal study.

The outcome of the study, namely parental perception of child behavioural problems, was assessed using the Child Behavioural Checklist for Ages 6-18 (CBCL/6-18), which was a validated, standardised, and a widely used scale for assessing behavioural problems amongst children and adolescents internationally. [13] Parents were asked to respond to 113 items that described specific behavioural and emotional problems that might occur in children and adolescents. These items were rated by parents on their perception of how true each item described their children now or within the past 6 months using a scale ranging from 0 to 2 ( $0=$ not true; $1=$ somewhat true or sometimes true; $2=$ very true or often true). The main content of the CBCL/6-18 covers 8 different domains including aggressive behaviour, anxious/depressed, attention problems, rule-breaking behaviour, social problems, somatic complaints, thought problems, and withdrawal. These eight domains are then further summarised into two main clusters of behavioural or emotive problems: internalisation (CBCL-inter) and externalisation (CBCL-exter) problems. A total score was also calculated for each child as an overall summary of the individual's behavioural problems (CBCL-total). Examples of these items included: "Can't concentrate, can't pay attention for long" for attention problems; "Cruel to animals" for aggressive behaviour; and "Unhappy, sad, or depressed" for anxious/depressed emotions. Higher total scores, internalisation, and externalisation scores, indicate a greater severity of behavioural or emotive problems. Ample studies have been conducted on the validity and reliability of the CBCL/6-18 with full information available on the Achenbach System of Empirically Based Assessment (ASEBA) official website [14].

Parental depression was measured using the depression subscale of the Hospital Anxiety and Depression Scale (HADS) which was designed as a self-reported screening instrument for depression. [15] The instrument has been used in many studies and its validity is well proven. [16] The depression subscale consists of 7 items assessing depressive affects. Examples of these items include: "I look forward with enjoyment to things" and "I have lost interest in my appearance". Respondents were asked to respond to questions of how often they had experienced these emotional states in the month prior to the survey. On a Likert scale, responses were rated from 0 to 3 for not at all to all of the time or some equivalent responses 
with total scores ranging from 0 to 21 . Responses were graded in a negative direction in a manner that higher scores represent greater depressive affects. Attachment or connectedness between parent and child was assessed using the Attachment Problems subscale of the Parental Stress Index (PSI). [17] The PSI was designed specifically to evaluate and to diagnose individual parent-child dyads under stress. Of different domains included in the instrument, attachment between parent and child is one "designed to measure the intrinsic investment the parent in the role of parent". [17] It was used to assess the degree of willingness parents would commit and attach in the relationship with their children. Parents were asked to rate how much they agree to a series of statements regarding their relationship with their children on a Likert scale ranging from 0 to 4 . Responses were graded in a direction with higher scores indicating greater attachment problems. An example item is "I expected to have closer and warmer feelings for my child than I do and this bothers me". The reliability and validity of the PSI have been demonstrated in many studies [17-19].

Other information collected in the survey included age and sex of the child, respondents' age and sex, parental education levels, occupation, family structure whether intact or divorced, family monthly incomes, and whether the parent suffered any chronic illnesses or hospitalisation. Included in the study were only parents of target children. Other responding relatives, such as grandparents, were excluded.

Data were analysed using the Stata V10.0 statistical software program. [20] Descriptive statistics on the sample including frequencies, percentages, means, standard deviations, and median were presented according to the nature of variables. All CBCL scores were treated as continuous variables. Bivariate analyses were conducted to examine unadjusted relationships between parental depression, attachment problems, demographics, and parental perception of child behavioural problems including the total, internalisation, and externalisation scores. Owing to the fact that CBCL-total, CBCL-inter, and CBCL-exter scores were highly skewed and exhibited problems of over dispersion, it was considered more appropriate to analyse these data with negative binomial regression models. Hence, this analytical technique was applied to all unadjusted and adjusted analyses. Bivariate associations between all variables of interest and parental perception of child behavioural problems were analysed with simple negative binominal regression models and were tested using the Likelihood Ratio Chi-squared tests. All significant variables identified from the bivariate analyses were included in further analyses for the adjusted relationship between parental depression, attachment problems and their perception of their children's behavioural problems. Of particular interest to the study was the interaction effect of parental depression and attachment problems between parent and child, on parental perception of children behavioural problems. Hence, the significance of interaction terms was tested in the final models for CBCL-total, CBCL-inter, and CBCL-exter scores.

\section{Results}

A total of 1839 parent-child dyads were recruited and provided usable information. This represented $97.1 \%$ of the total participants of the longitudinal study. Fifty-six respondents 
were not parents of the targeted child. The characteristics of children and their parents including parental depression, attachment problems, and parental perception of behavioural problems were summarised in Table 1 . In terms of the outcome variables, the mean values of all CBCL scores were larger than their corresponding median values with large standard deviations suggesting all three scores were skewed and had problems of over dispersion.

\begin{tabular}{|c|c|}
\hline Variables & Frequency (\%) or mean (s.d.), median \\
\hline \multicolumn{2}{|l|}{ Demographics } \\
\hline Age of the child (years) & Mean $=9.5(0.61)$, median $=9.5$ \\
\hline Sex of child & $958(52.2)$ \\
\hline Male & $876(47.8)$ \\
\hline \multicolumn{2}{|l|}{ Female } \\
\hline Age of parent (years) & Mean=38.7 (4.11), median=38.1 \\
\hline Relation of parent to child & $767(42.7)$ \\
\hline Father & $1031(57.3)$ \\
\hline \multicolumn{2}{|l|}{ Mother } \\
\hline Family structure & 1624 (89.8) \\
\hline Living with both biological parents & $184(10.2)$ \\
\hline \multicolumn{2}{|l|}{ Others } \\
\hline Parent's education level & $920(51.1)$ \\
\hline High school or lower & $418(23.2)$ \\
\hline Post secondary & $462(25.7)$ \\
\hline \multicolumn{2}{|l|}{ University or higher } \\
\hline Parent's occupation & $232(13.1)$ \\
\hline Unemployed /retired & $465(26.4)$ \\
\hline Farmer/labourer & $425(24.1)$ \\
\hline Government official & $201(11.4)$ \\
\hline \multicolumn{2}{|l|}{ Professional/technical } \\
\hline \multicolumn{2}{|l|}{ Business } \\
\hline Monthly income $(\mathrm{RMB} \$)^{\star}$ & $601(35.2)$ \\
\hline Low & $522(30.5)$ \\
\hline Middle & $586(34.3)$ \\
\hline \multicolumn{2}{|l|}{ High } \\
\hline Parent having chronic disease or hospitalised & $292(15.9)$ \\
\hline Yes & $1547(84.1)$ \\
\hline No & \\
\hline
\end{tabular}




\begin{tabular}{lc}
\hline Variables & Frequency (\%) or mean (s.d.), median \\
\hline Parental Stress Index -Attachment Problems scores & Mean=18.4 (3.35), median=18.0 \\
\hline Parental depression HADS depression scores & Mean=4.7 (3.04), median=4.0 \\
\hline CBCL-Total scores & Mean=21.1 (17.66), median=18.0 \\
\hline CBCL Internalisation scores & Mean=5.8 (5.79), median=4.0 \\
\hline CBCL Externalisation scores & Mean=7.9 (7.06), median 6.0 \\
\hline$*$ LoW $<$ RMB $\$ 3000 ;$ middle 3000-4900; high>5000 & \\
\hline
\end{tabular}

Table 1. Description information on the characteristics of children, their parents, parent-child attachment problems, parental depression, and parental perception of child behavioural problems ( $\mathrm{N}=1839)$

\begin{tabular}{|c|c|c|c|}
\hline \multirow[b]{2}{*}{ Variables } & \multicolumn{3}{|c|}{ Results on association } \\
\hline & $\mathrm{CBCL}$ total & Internalisation & Externalisation \\
\hline \multicolumn{4}{|l|}{ Demographics } \\
\hline Age of the child & $x^{2}{ }_{1}=2.52, p=0.112$ & $x^{2}{ }_{1}=0.49, p=0.485$ & $x^{2}=3.81, p=0.051$ \\
\hline Sex of child & $x^{2}{ }_{1}=23.77, p<0.001$ & $\mathrm{x}^{2}{ }_{1}=4.50, p=0.034$ & $x^{2}{ }_{1}=50.18, p<0.001$ \\
\hline Age of parent & $x^{2}{ }_{1}=16.01, p<0.001$ & $\mathrm{X}^{2}{ }_{1}=8.09, \mathrm{p}=0.0042$ & $x^{2}{ }_{1}=23.69, p<0.001$ \\
\hline Relation of parent to child & $x^{2}{ }_{1}=1.13, p=0.288$ & $x^{2}{ }_{1}=0.62, p=0.432$ & $x^{2}{ }_{1}=1.14, p=0.216$ \\
\hline Family structure & $x^{2}{ }_{1}=2.16, p=0.141$ & $x^{2}=2.50 p=0.114$ & $x^{2}=1.85, p=0.174$ \\
\hline Parent's education level & $x_{2}^{2}=5.90, p=0.052$ & $\mathrm{X}_{2}^{2}=4.32, \mathrm{p}=0.115$ & $x_{2}^{2}=3.95, p=0.139$ \\
\hline Parent's occupation & $x^{2}{ }_{4}=5.34, p=0.254$ & $\mathrm{X}^{2}{ }_{4}=7.21, \mathrm{p}=0.125$ & $x^{2}{ }_{4}=3.70, p=0.449$ \\
\hline Monthly income & $x_{2}^{2}=5.32, p=0.007$ & $x_{2}^{2}=2.67, p=0.263$ & $x_{2}^{2}=7.55, p=0.023$ \\
\hline $\begin{array}{l}\text { Parent having chronic disease or } \\
\text { hospitalised }\end{array}$ & $x^{2}{ }_{1}=22.65, p<0.001$ & $x^{2}{ }_{1}=27.31, p<0.001$ & $x^{2}{ }_{1}=25.36, p<0.001$ \\
\hline $\begin{array}{l}\text { Parental Stress Index -Attachment } \\
\text { Problems scores }\end{array}$ & $X^{2}{ }_{1}=12.13, p<0.001$ & $x_{1}{ }_{1}=19.22, p<0.001$ & $x_{1}^{2}=12.38, p<0.001$ \\
\hline $\begin{array}{l}\text { Parental depression HADS } \\
\text { depression scores }\end{array}$ & $x^{2}{ }_{1}=42.52, p<0.001$ & $x^{2}{ }_{1}=50.62, p<0.001$ & $x^{2}{ }_{1}=28.83, p<0.001$ \\
\hline
\end{tabular}

Table 2. Unadjusted associations between child and parent characteristics and parental perception on child behavioural problems: CBCL Total; CBCL-Internalisation: and CBCL-Externalisation

The bivariate relationships between demographics, parental depression, attachment problems and parental perception of child behavioural problems were examined. The results were summarised in Table 2. As shown, among the demographic variables, child's sex, parents' age, monthly income, and parental illness were significantly associated with all three 
CBCL scores. Results also suggested the unadjusted association between parental depression and the perception of their children's behavioural problems was highly significant for all CBCL scores (CBCL-total: $\chi_{1}^{2}=42.52, \mathrm{p}<0.001$; CBCL-inter: $\chi_{1}^{2}=50.62, \mathrm{p}<0.001$; CBCL-exter: $\chi_{1}^{2}=28.83, \mathrm{p}<0.001$ ). This also applied to attachment problems (CBCL-total: $\chi_{1}^{2}=12.13$, $\mathrm{p}<0.001$; CBCL-inter: $\chi^{2}{ }_{1}=19.22, \mathrm{p}<0.001$; CBCL-exter: $\left.\chi^{2}{ }_{1}=12.38, \mathrm{p}<0.001\right)$.

\begin{tabular}{|c|c|c|c|c|}
\hline \multirow[b]{2}{*}{ Variables in the final model } & \multicolumn{4}{|c|}{ Results } \\
\hline & $\beta$ & $\operatorname{SE}(\beta)$ & Z-value & $p$-value \\
\hline & \multicolumn{4}{|c|}{ CBCL-Total } \\
\hline Female & -0.21 & 0.047 & -4.45 & $<0.001$ \\
\hline Parent's age & -0.02 & 0.006 & -3.66 & $<0.001$ \\
\hline Parent having chronic disease or hospitalised & 0.25 & 0.062 & 3.94 & $<0.001$ \\
\hline Attachment problems & 0.03 & 0.007 & 3.32 & 0.001 \\
\hline \multirow[t]{2}{*}{ Parental depression } & 0.05 & 0.008 & 5.71 & $<0.001$ \\
\hline & \multicolumn{4}{|c|}{ CBCL-Internalisation } \\
\hline Parent's age & -0.02 & 0.007 & -2.49 & 0.013 \\
\hline Parent having chronic disease or hospitalised & 0.31 & 0.070 & 4.50 & $<0.001$ \\
\hline Attachment problems & 0.03 & 0.008 & 3.97 & $<0.001$ \\
\hline \multirow[t]{2}{*}{ Parental depression } & 0.06 & 0.001 & 5.96 & $<0.001$ \\
\hline & \multicolumn{4}{|c|}{ CBCL-Externalisation } \\
\hline Female & -0.31 & 0.047 & -6.605 & $<0.001$ \\
\hline Parent's age & -0.03 & 0.006 & -4.72 & $<0.001$ \\
\hline Parent having chronic disease or hospitalised & 0.24 & 0.063 & 3.79 & $<0.001$ \\
\hline Attachment problems & 0.03 & 0.008 & 3.37 & 0.001 \\
\hline Parental depression & 0.04 & 0.008 & 4.25 & $<0.001$ \\
\hline
\end{tabular}

Table 3. Results obtained from the multiple negative binomial regression analyses on CBCL Total, CBCLInternalisation, and CBCL-Externalisation without interaction terms.

The results obtained from the multiple negative binomial regression analyses were also presented in Table 3 and Table 4. Table 3 presented results on final regression models of CBCL scores, including the total, internalisation, and externalisation, regressing on various study variables with terms of interaction between parental depression and attachment problems included. Results indicated the interaction term in the final model for CBCL-exter was significant $(Z=2.19, p=0.029)$, suggesting that there was a significant interaction effect of parental depression and attachment problems between parent and child on the perception of their children's behavioural problems. 


\begin{tabular}{|c|c|c|c|c|}
\hline \multirow[b]{2}{*}{ Variables in the final model with interaction term } & \multicolumn{4}{|c|}{ Results } \\
\hline & $\beta$ & $\operatorname{SE}(\beta)$ & Z-value & p-value \\
\hline & \multicolumn{4}{|c|}{ CBCL-Total } \\
\hline Female & -0.21 & 0.047 & -4.45 & $<0.001$ \\
\hline Parent's age & -0.02 & 0.006 & -3.61 & $<0.001$ \\
\hline Parent having chronic disease or hospitalised & 0.25 & 0.062 & 3.99 & $<0.001$ \\
\hline Attachment problems & 0.04 & 0.012 & 3.18 & 0.001 \\
\hline Parental depression & 0.11 & 0.046 & 2.41 & 0.016 \\
\hline \multirow[t]{2}{*}{ Interaction: Attachment*Parental depression } & 0.01 & 0.002 & 1.42 & 0.155 \\
\hline & \multicolumn{4}{|c|}{ CBCL-Internalisation } \\
\hline Parent's age & -0.02 & 0.007 & -2.45 & 0.014 \\
\hline Parent having chronic disease or hospitalised & 0.32 & 0.070 & 4.51 & $<0.001$ \\
\hline Attachment problems & 0.04 & 0.014 & 2.84 & 0.004 \\
\hline Parental depression & 0.08 & 0.053 & 1.54 & 0.124 \\
\hline \multirow[t]{2}{*}{ Interaction: Attachment*Parental depression } & 0.01 & 0.003 & 0.51 & 0.611 \\
\hline & \multicolumn{4}{|c|}{ CBCL-Externalisation } \\
\hline Female & -0.34 & 0.048 & -7.01 & $<0.001$ \\
\hline Parent's age & -0.03 & 0.006 & -4.09 & $<0.001$ \\
\hline Parent having chronic disease or hospitalised & 0.25 & 0.063 & 4.00 & $<0.001$ \\
\hline Attachment problems & 0.05 & 0.013 & 4.02 & $<0.001$ \\
\hline Parental depression & 0.13 & 0.046 & 2.90 & 0.004 \\
\hline Interaction: Attachment*Parental depression & 0.01 & 0.002 & 2.19 & 0.029 \\
\hline
\end{tabular}

Table 4. Results obtained from the multiple negative binomial regression analyses on CBCL Total, $C B C L$ Internalisation, and CBCL-Externalisation with interaction terms.

Figure 1 depicted the unadjusted mean scores of externalisation behaviour for different parental depression status by different levels of attachment problems. The figure exhibited a lack of parallelism suggesting an interaction effect between parental depression and parentchild attachment on the CBCL-exter scores. The interaction terms in models for CBCL-total and CBCL-inter were not significant. Table 4 presented results on the final models of CBCLtotal and CBCL-inter after removal of the interaction terms. As shown, parental depression and attachment problems between parent and child were significantly related to parental perception of their children's behavioural problems for both the total (depression: $Z=5.71$, $p<0.001$ : attachment: $Z=3.32, p=0.001$ ) and internalisation (depression: $Z=5.96, p<0.001$ : attachment: $Z=3.97, p<0.001)$ scores after adjusting for sex, parental age, and parental illness. 


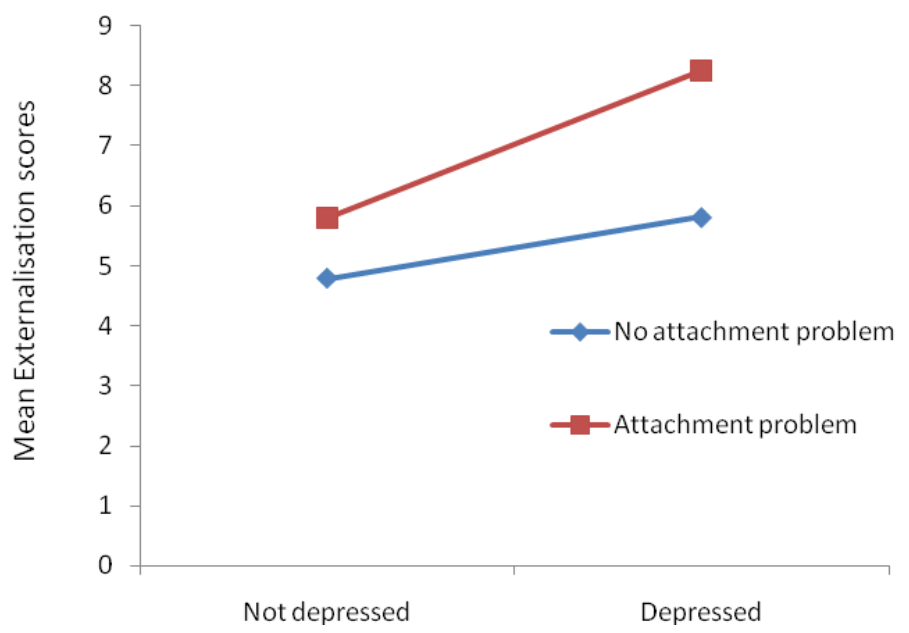

Figure 1. Plot of mean externalisation scores of parental depression status by attachment problems, ${ }^{*}$ Depression status was classified using a cut-off suggested by the HADS author ( $>7=$ depressed); Attachment problems was clssified using a cut-off of $>15$ as suggested by the PSI author.

\section{Discussion and conclusion}

This study aims to examine the relationship between parental depression, parent-child relationship and parental perception of children's behavioural/emotional problems. Particularly, it aims to test the hypothesis of the interaction effect of parental depression and parentchild attachment on parental perception of children's behavioural/emotional problems. The results provided evidence of a significant interaction effect between parental depression and parent-child attachment problems on parental perception on the externalising of children's problems, but no effects on internalising problems and total problems. The main effects of parental depression and parent-child attachment problems on parental perception of children behavioural/emotional problems were found significant.

Due to the lack of a similar study on the interaction between parental depression and attachment problem and parental perception on children's behavioural/emotional problems, a comparison of results obtained from this study with others reported in literature would be difficult. However, other results obtained from the study are consistent with those obtained in the general literature of parental depression, parent-child relationships and the distortion of parental perception of children's behavioural/emotional problems as highlighted in the introduction section. For example, in the study by Treutler et al, it was found that parental depression and parent-child relationship were both associated with their ratings on internalising behaviours. [5] The results of the current study have rendered further support to this finding. Furthermore, it has shown that parental perception of children's externalising be- 
havioural problems is a function of their own depressive symptomatologies and the attachment to their children.

The results indicated that attachment between parent and child acts as an effect modifier in the relationship between parental depression and their perception of children's externalising behavioural problems. For parents who have a close relationship with their children, it could be considered natural that depression would influence their perception of children's behavioural problems. However, for parents who have experienced attachment problems with their children as well as depression, the alienated relationship with their children tends to enhance their perception of children's behavioural problems to such a degree that is much more than the usual effect brought on by depression alone. In other words, the alienated relationship enhances the effect of depression on parental perception of children's behavioural problems. It is interesting to note that such an interactive effect is observed for externalising behavioural problems, but not for internalising problems. One possible explanation for this phenomenon is that externalising behavioural problems, including aggressive behaviour, rule-breaking, and attention problems, are observable manifestations of childhood problems. Parents can identify these behaviours and perceive them as problematic easily for both depressive and non-depressive parents, with depressive parents labelling them with a greater degree of severity. However, if the parent-child dyad has been experiencing a detrimental relationship, it is likely that the parent would have a heightened sensitivity to the child's observable behavioural problems. This heightening of awareness or sensitivity is further enhanced in a parent who is also experiencing depression. This heightening of awareness may be absent for those less observable behavioural problems such as withdrawal and depression.

The results obtained from this study have a direct clinical implication on the validity of using parents as informants for children's behavioural assessments. As above-mentioned, parental distortion in their report on children's behavioural assessments has long been identified and established as a potential source of error. [7] The results of this study further indicate that parents' perception of their children's behaviour is a function of their own internal state as well as their relationship with their children. The potential for distortion in reporting of child behaviour is great if a single parent is used as the sole informant. Should this aspect be overlooked, systematic biases would result due to distortion errors. This may occur in research as well as in clinical assessment. In fact, it has been advocated that multiple informants, especially non-familial informants, should be used for any childhood behavioural problems in both research and clinical settings. [21-22] If possible, observational tools instead of self-reported instruments should be employed and non-family observers should be used as informants. [23] In the current longitudinal study, children who have been identified with scores higher than the recommended cut-off will be assessed by a child psychiatrist using another clinical assessment tool.

In terms of prevention and early intervention of developmental psychopathology in children, the results of the study can also shed some lights. Tackling attachment problems be- 
tween parents and their children may provide an inroad to, not only the change of perception of child behavioural problems but also, the actual developmental problems during early childhood and behavioural problems throughout the entire child and adolescence period. A recent study has identified that the quality of interaction between mother and child, particularly in the area of emotion availability of the mother, has a direct bearing on the functioning, behavioural problems, and depressive symptomatologies of the child. [24] In this longitudinal study, it has been found that dysfunctional mother-child relationship and poor attachment at infancy is predictive of developmental and behavioural problems at later years of childhood. [24] However, early intervention program in enhancing attachment between parent and child could have a positive effect in improving the quality of parentchild relationship and reinforcing a secure attachment. [25] This could, in turn, have a direct impact on the on-going development of the child. Furthermore, it could also be possible that the problematic parent-child relationship may have contributed to the depression of the parent. An improvement in parent-child attachment could have an alleviating effect of the parent's depression and, in turn, reinforcing a better relationship with the child and resulting in a better behavioural outcome.

As in all studies, there are strengths and weaknesses in this study. This is a populationbased study that includes a random sample of students. The use of a standardised and validated assessment instrument for the outcome measure minimised some measurement biases. The assessments on parental depression, parent-child relationship, and parental perception of children's behavioural problems were concurrent and captured the current status on all these variables, hence minimising biases due to the lapse of time. A potential limitation has been identified in this study. Information on the exposure variables, namely parental depression and attachment problems is obtained via a self-reported questionnaire. Hence this will constitute a report bias in the exposure variables and it would likely present as a differential bias due to depressive parents reporting more severe symptomatologies as well as parent-child relationship problems. To improve the quality of the study, parental depression and parent-child relationships are best to be assessed by multiple informants as well as by observers as suggested by [23].

\section{Author details}

Lawrence T. Lam ${ }^{1,2}$

Address all correspondence to: lawrence.lam@nd.edu.au

1 The School of Medicine Sydney, The University of Notre Dame, Sydney, Australia

2 Discipline of Paediatrics and Child Health, Sydney Medical School, The University of Sydney, Australia 


\section{References}

[1] Breslau, N., Davis, G. C., \& Prabucki, K. (1988). Depressed mothers as informants in family history research- are they accurate? Psychiatry Research, 24, 345-59.

[2] Richters, J.E. (1992). Depressed mothers as informants about their children: a critical review of the evidence for distortion. Psychological Bulletin, 112, 485-99.

[3] Fergussen, D. M., Lynskey, M. T., \& Horwood, L. J. (1993). The effect of maternal depression on maternal ratings of child behaviour. Journal of Abnormal Child Psychology, $21,245-69$.

[4] Connell, A. M., \& Goodman, S. H. (2002). The association between psychopathology in fathers versus mothers and children's internalizing and externalizing behaviour problems: a meta-analysis. Psychological Bulletin, 128, 746-73.

[5] Treutler, C. M., \& Epkines, C. C. (2003). Are discrepancies among child, mother, and father reports on children's behaviour related to parents' psychological symptoms and aspects of parent-child relationships? Journal of Abnormal Child Psychology, 31, 13-27.

[6] Luoma, I., Koivisto, A. M., \& Tamminen, T. (2004). Fathers' and mothers' perceptions of their child and maternal depressive symptoms. Nordic Journal of Psychiatry, 58, 205-11.

[7] Hall, L. A., Rayens, M. K., \& Peden, A. R. (2008). Maternal factors associated with child behaviour. Journal of Nursing Scholarship, 40, 124-30.

[8] Ackard, D. M., Neumark-Sztainer, D., Story, M., \& Perry, C. (2006). Parent-child connectedness and behavioural and emotional health among adolescents. American Journal of Preventive Medicine, 30, 59-66.

[9] Liu, Y.L. (2006). Parental/maternal attachment, peer support, social expectations of peer interaction, and depressive symptoms. Adolescence, 41, 705-21.

[10] Kolko, D. J., \& Kazdin, A. E. (1993). Emotional/behavioural problems in clinic and nonclinic children: Correspondence among child, parent, and teacher reports. Journal of Child Psychology and Psychiatry, 34, 991-1006.

[11] Mosley, J., \& Thompson, E. (1995). Fathering behaviour and child outcome: The role of race and poverty. Marsiglio W. (ed.) Fatherhood: Contemporary theory, research, and social policy. Beverly Hills: Sage, 148-165.

[12] Burke, L. (2003). The impact of maternal depression on familial relationships. International Review of Psychiatry, 15, 243-55.

[13] Achenbach, T.M. Manual for CBCL 6-18 years. Burlington: ASEBA; 2001.

[14] Achenbach, TM. (2009). Achenbach System of Empirically Based Assessment. http:// www.aseba.org/index.html, (accessed 15 January 2012). 
[15] Zigmond, A.S., \& Snaith, R.P. (1983). The Hospital Anxiety And Depression Scale. Acta Psychiatricia Scandinavica, 67, 361-70.

[16] Bjelland, I., Dahl, A. A., Haug, T. T., \& Neckelmann, D. (2002). The validity of the Hospital Anxiety and Depression Scale. An updated literature review. Journal of Psychosomatic Research, 52, 69-77.

[17] Abidin, R.R. (1995). Parenting Stress Index (PSI) manual $3^{\text {rd }}$ Edition. Charlottesville: Pediatric Psychology Press.

[18] Hutcheson, J., \& Black, M. (1996). Psychometric properties of the Parenting Stress Index in a sample of low-income African-American mothers of infants and toddlers. Early Education Development, 7, 381-400.

[19] Ostberg, M., Hagekull, B., \& Wettergren, S. (1997). A measure of parental stress in mothers with small children, dimensionality, stability, and validity. Scandinavian Journal of Psychology, 38, 199-208.

[20] StataCorp. (2007). Stata Statistical Software: Release 10.0. College Station: StataCorporation.

[21] Soussingan, R., Tremblay, R. E., Schaal, B., et al. (1992). Behavioural and cognitive characteristics of conduct disordered-hyperactive boys from age 6 to 11: a multiple informant perspective. Journal of Child Psychology and Psychiatry, 33, 1333-46.

[22] Kristensen, H. (2001). Multiple informants' report of emotional and behavioural problems in a nation-wide sample of selective mute children and controls. European Child and Adolescent Psychiatry, 10, 35-42.

[23] Cunningham, C.E. (2007). A family-centred approach to planning and measuring the outcome of interventions for children with attention-deficit/hyperactivity disorder. Journal of Pediatric Psychology, 32, 676-94.

[24] Easterbrooks, M. A., Bureau, J. F., \& Lyons-Ruth, K. (2012). Developmental correlates and predictors of emotional availability in mother-child interaction: a longitudinal study from infancy to middle childhood. Developmental Psychopathology, 24, 65-78.

[25] Wendland-Carro, J., Piccinini, C.A., \& Millar, W.S. (1999). The role of an early intervention on enhancing the quality of mother-infant interaction. Child Development, 70 , $713-21$ 
